\title{
Long Intergenic Non-Protein Coding RNA 44
}

National Cancer Institute

\section{Source}

National Cancer Institute. Long Intergenic Non-Protein Coding RNA 44. NCI Thesaurus. Code C132182.

Long intergenic non-protein coding RNA $44(\sim 0.5 \mathrm{~kb})$ is encoded by the human SNHG5 gene. This non-coding RNA plays a role in the synthesis of small nucleolar RNAs U50 and U50'. 